\title{
Cerebralcare Granule $\circledast$ enhances memantine hydrochloride efficacy in APP/PS1 mice by ameliorating amyloid pathology and cognitive functions
}

\section{Ou Qiao}

Tianjin University

\section{Xinyu Zhang}

Tianjin University

\section{Yi Zhang}

Tianjin University

Haixia Ji

Tianjin University

Zhi Li

Tianjin University

\section{Xiaoying Han}

Tianjin University

\section{Wenzhe Wang}

Tianjin University

\section{Xia Li}

Tianjin University

\section{Juan Wang}

Tianjin University

\section{Changxiao Liu}

The State Key Laboratories of Pharmacodynamics and Pharmacokinetics

\section{Wenyuan Gao ( $\sim$ pharmgao@tju.edu.cn )}

Tianjin University

\section{Research}

Keywords: Alzheimer' s disease, Cerebralcare Granule $®$, memantine hydrochloride, cognitive impairments, synaptic plasticity, $A \beta$ plaque accumulation, complementary medicine

Posted Date: April 8th, 2021 
DOl: https://doi.org/10.21203/rs.3.rs-366097/v1

License: (c) (1) This work is licensed under a Creative Commons Attribution 4.0 International License. Read Full License 


\section{Abstract \\ Background}

Alzheimer's disease (AD) is a progressive neurodegenerative disease characterized by memory deficits and cognitive decline. Current drugs can only relieve symptoms, but cannot really cure AD. Cerebralcare granule ${ }^{\circledR}(C G)$ is a Traditional Chinese medicine (TCM) containing a variety of biologically active compounds. In our previous studies, $\mathrm{CG}$ has shown a beneficial effect on memory impairment in mice caused by D-galactose. However, whether CG can be used as a complementary medicine for the treatment of $A D$ remains unexplored. Here, we use a combination of $C G$ and memantine hydrochloride $(\mathrm{Mm})$ to treat Alzheimer-like pathology and investigate the effects and mechanisms in vivo.

\section{Methods}

The histology of brain was examined with Hematoxylin-eosin (HE) staining, Golgi staining and Thioflavin $S$ staining. ELISA was applied to assess the expression levels or activities of CAT, SOD, GSH-Px, MDA, alanine aminotr-ansferase (ALT), aspartate aminotransferase (AST), alkaline phosphatase (ALP), total bilirubin (TBIL) in serum, as well as the levels of IL-6, IL-1 $\beta$, and TNF-a in the mice brain. Western blotting was used to assess the expression of $\beta$-secretase (BACE1), amyloid precursor protein (APP), APP $\beta, A P P a$, synaptophysin (SYN), growth-associated protein 43 (GAP43), and postsynaptic density 95 (PSD95).

\section{Results}

In the present study, the combination group $(C G+M m)$ significantly attenuated Alzheimer-like behavior without adverse effects in APP/PS1 mice, indicating its high degree of safety and efficacy after long-term treatment. $C G+M m$ reduced $A D$ pathological biomarker $A \beta$ plaque accumulation by inhibiting BACE1 and APP expression, while $\mathrm{Mm}$ has no similar effect. Besides, the combination group markedly inhibited the levels of IL-1 $1 \beta$, IL- 6 , and TNF- $\alpha$ in the hippocampus, as well as activities of SOD, CAT, and GSH-Px in serum. By contrast, the combination group improved synaptic dysfunction by enhancing SYN, PSD95, and GAP43 expression.

\section{Conclusions}

Taken together, these data supported the notion that CG might ameliorate the cognitive impairment through multiple pathways, suggesting that $C G$ could play a role as complementary medicine to increase anti-AD effect of chemical drugs by reducing $A \beta$ deposition, neuroinflammation, oxidative damage, and improving synaptic.

\section{Background}


$A D$ is the most common form of dementia affecting the elderly [1]. AD patients suffered progressive cognitive and functional deficits, which resulted in a heavy burden to patients, families, and the public health system [2]. In 2019, AD affected more than 50 million people globally, which is expected to reach 152 million by 2050 . In addition, the current annual cost of AD worldwide is $\$ 1$ trillion, which is estimated to double by 2030 [3]. Rising prevalence and mortality, and the lack of effective treatments, have resulted in huge costs to society. Currently, cholinesterase inhibitors (i.e., donepezil) and Nmethyl-D-aspartate (NMDA) receptor antagonists (i.e., memantine) are approved by FDA for the treatment of AD. However, these drugs can only moderately relieve symptoms and cannot really cure AD. Therefore, we need to find new treatment options to slow down the progression of $A D$.

Accumulation of $A \beta$ is considered to be one of the main pathogenic features of $A D$, which causes a series of neuronal damage [4], leading to cognitive dysfunction [5]. A $\beta$ plaques affect synaptic morphology and function by disrupting the synaptic signaling pathway, leading to memory loss and behavioral changes [5]. Moreover, $A \beta$ oligomers deposited extracellular can also activate microglia and subsequently release inflammatory cytokines, the amount of APP will increase due to the large release of these factors. As the amount of APP increases, the production of $A \beta$ becomes higher $[6,7]$. Severe oxidative stress and neuroinflammation, loss of synaptic connections in specific brain regions, cumulative emergence of intracellular tau pathology, and accumulation of extracellular amyloid $A \beta$ plaques form a complex neurodegeneration $[8,9]$. Therefore, we believe that it is difficult to cure the complex disease with multiple pathological factors by single target chemical drugs. CG (Tianjin Tasly Pharmaceutical Co., Ltd, Tianjin, China) was approved by the National Medical Products Administration (NMPA) in 1996 for treatment of headache and dizziness associated with cerebrovascular diseases. It is consists of 11 herbs, including Angelicae Sinensis Radix, Paeoniae Radix Alba, Chuanxiong Rhizoma, Rehmanniae Radix Praeparata, Uncariae Ramulus Cum Uncis, Spatholobi Caulis, Corydalis Rhizoma, Prunellae Spica, Margarita, Cassiae Semen, and Asari Radix et Rhizoma. These 11 herbs contain a large number of chemical components. Some of these ingredients are key to the treatment of diseases in traditional Chinese medicine and are the main sources of new drug lead compounds [10]. For example, paeoniflorin, albiflorin, rosmarinic acid, chlorogenic acid, tetrahydropalmatine, caffeic acid, gallic acid, and ferulic acid (Fig. 1c) are known to improve learning and memory deficits, attenuate neurotoxicity, and anti-oxidant damage [11-15].

Previous studies have shown that the ingredients mentioned above can be detected in blood of mice after oral administration of CG $[16,17]$. Due to the complicated mechanisms of TCM, these ingredients were usually used as part of a combination therapy rather than monotherapy [18]. Studies have shown that as a supplementary treatment of modern medicine, TCM improved the therapeutic effect of modern medicine. For example, after intraperitoneal injection of pentobarbital sodium, rats were given He jie Zhitong prescription by gavage, the sleep latency of rats was significantly decreased, and the sleep time was prolonged, suggesting that Hejie Zhitong prescription exerted a synergistic effect with pentobarbital sodium [19]. Shufeng Jiedu Capsule enhanced doxorubicin therapeutic efficacy in hepatocellular carcinoma by inhibiting migration and invasion [20]. Fuzheng Kang Ai decoction combined with erlotinib enhances the effect of lung cancer treatment [21]. Xiaoaiping injection enhanced paclitaxel efficacy in ovarian cancer proliferation by inhibiting pregnane $X$ receptor [22]. Huyang Yangkun Formula could 
enhance the therapeutic effect of embryonic stem cells on premature ovarian failure mice. This combined therapy could promote the development of mice follicles and inhibit the expression of the TGF- $\beta 1 /$ TAK1 pathway [23]. These results suggest that the combination therapy of TCM and western medicine is feasible in the treatment of various diseases. However, there were no studies on attenuation Alzheimerlike pathology of combination therapy of CG and other chemotherapy drugs.

$\mathrm{Mm}$ is a moderate-affinity, uncompetitive NMDA receptor antagonist. It is used to improve cognitive and behavioral disorders in moderate to severe $A D$ patients $[24,25]$. To illustrate whether $C G$ can enhance the therapeutic effect of Mm on AD, and explain the potential synergies, the APP/PS1 mice model was used to solve the puzzle. As a result, the combination of $C G$ and $M m$ had a stronger anti-AD effect than the single treatment. Meanwhile, the expressions of PSD95, SYN, GAP43, APP, APP $\beta$, APPa, and BACE1 have correspondingly changed, which may be the reason for the synergistic anti-Alzheimer's efficacy.

Our work provides a comprehensive explanation for the synergistic effect of CG combined with Mm against Alzheimer's disease in terms of anti-inflammatory, anti-oxidant damage, reducing $A \beta$ deposition and maintaining synaptic connections, providing a new idea combination therapy of Alzheimer's disease for the combination treatment of Chinese medicine and Chemical drugs.

\section{Methods And Materials}

\section{HPLC-QQQ-MS/MS analysis condition}

CG was ultrasonically extracted with $10 \mathrm{~mL}$ of $70 \%$ methanol for $30 \mathrm{~min}$ (weight: volume $=1: 10$ ). The weight loss was made up with $70 \%$ methanol. The extract was centrifuged at $4000 \mathrm{rpm}$ for $10 \mathrm{~min}$ and the supernatant was filtered by a $0.22 \mathrm{~mm}$ filter before analysis. The chemical constituents of CG were analyzed by Agilent 1200 series HPLC system (Agilent Technologies, USA) connected with the electrospray ionization tandem triple quadrupole mass spectrometry (ESI-QQQ-MS, Bruker Daltonics Inc., USA). Chromatographic separation was performed on a Kromasil 100-5-C18 column (4.6 mm× $250 \mathrm{~mm}, 5$ $\mu \mathrm{m})$ using two mobile phases: ultrapure water with $0.1 \%$ formic acid $(A)$ and acetonitrile (B). The gradient elution program was shown as follows: 0-5 min, 5-10\% B; 5-30 min, 10-25\% B; 30-58 min, 25-65\% B; $58-78 \mathrm{~min}, 68-88 \% \mathrm{~B} ; 78-85 \mathrm{~min}, 88-93 \% \mathrm{~B} ; 85-95 \mathrm{~min}, 95-5 \%$ B. The flow rate: $1 \mathrm{~mL} / \mathrm{min}$, the column temperature was $28^{\circ} \mathrm{C}$, and the injection volume: $10 \mu \mathrm{L}$. The MS analysis was worked using full scan mode and the mass range was recorded from m/z 100 to 1000 both in positive mode and negative mode. The MS conditions were as follows: drying gas $\left(\mathrm{N}_{2}\right)$ flow rate, $8.0 \mathrm{~L} / \mathrm{min}$; the drying gas temperature was set to $320^{\circ} \mathrm{C}$; nebulizer pressure: 40 psig; capillary voltage: $3000 \mathrm{~V}$; fragmentor voltage: 135 V. Bruker Compass Data Analysis software Version 4.3 (Bruker Daltonics GmbH, Bremen, Germany) was used for data acquisition and analysis.

\section{Animals and Drug Administration}

Six month old male C57BL/6J wild-type mice and APP/PS1 mice were provided by the SPF (Beijing) Biotechnology Co., Ltd in China (license no. SCXK (Jing) 2019-0010). All mice were adaptively reared for 
one week before the initiation of experimentation. The mice were kept in standard cages at $23 \pm 2^{\circ} \mathrm{C}$ under $12 \mathrm{~h} / 12 \mathrm{~h}$ light/dark conditions and a humidity of $40 \pm 5 \%$, and they were provided with mice food and water ad libitum. All experimental protocols were conducted according to guidelines of the Institutional Animal Care and Use Committee of Institute of Radiation Medicine Chinese Academy of Medical Sciences (Tianjin, China). The mice were randomly divided into five groups (10 mice per group): Wild type group (WT, saline), APP/PS1 mice group ( $\mathrm{gg}$, saline), CG group ( $2.46 \mathrm{~g} / \mathrm{kg}$, based on clinical dosage), Mm group (Mm, $5 \mathrm{mg} / \mathrm{kg}$, according to the Zhang JH et al. [26]), CG combined with Mm group (CG + Mm, 2.46 $\mathrm{mg} / \mathrm{kg}, 5 \mathrm{mg} / \mathrm{kg}$, respectively). The treatments were administered intragastricly once daily for 4 weeks. After treatment, The Morris water maze test and Open-field test were used to evaluate cognitive ability and behavioral changes of mice.

\section{Morris water maze (MWM) test}

The MWM video tracking analysis system (Beijing Zhishuduobao Biological Technology Co., Ltd. China) was used to assess the learning and memory ability of mice in spatial position and orientation after treatment. The water depth of the MWM system was $20 \mathrm{~cm}$, the diameter was $120 \mathrm{~cm}$, and the water temperature was $(23 \pm 2)^{\circ} \mathrm{C}$. The platform was placed in the second quadrant, submerged about one $\mathrm{cm}$ below the water surface. In brief, Spatial training to find the target platform hidden in the water and was performed consecutively for six days. During the acquisition phase (days 1-6), animals that failed to find the platform within $60 \mathrm{~s}$ were manually guided to the platform and given $20 \mathrm{~s}$ to stay. The escape latency (EL) for finding the submerged platform was regarded as $60 \mathrm{~s}$. Twenty-four hours after the final spatial training, the probe test was performed by removing the platform and giving each mice to swim freely for $60 \mathrm{~s}$. The number of times they crossed platform and the time in the second quadrant were automatically recorded by the MWM video tracking system. The experimental scheme as shown in Fig. 2a.

\section{Open field test (OFT)}

The experimental device was a square Plexiglas box, the bottom plate was divided into 25 squares by white lines, and the wall was a black color. The mice were placed in the same position in the box, and the total distance traveled of mice within 5 min was recorded by a video tracking system at the top of the experimental platform. The field instrument was swabbed with $75 \%$ alcohol to avoid leaving an abnormal odor after each mice had finished recording. The following observations were made: number of square crossings, exercise time and the trajectories of the mice.

\section{Chemicals and Antibodies}

CG was obtained from Tianjin Tasly Pharmaceutical Co., Ltd (Tianjin, China). Mm was obtained from $\mathrm{H}$. Lundbeck A/S (Denmark). MDA, CAT, GSH-Px, SOD, IL-6, IL-1 $\beta$, and TNF-a ELISA kits were obtained from Shanghai FANKEL Industrial Co., Ltd (Shanghai, China). ALT, AST, ALP, and TBIL assay kits were purchased from Nanjing Jiancheng Bioengineering Research Institute (Nanjing, China). The following antibodies A $\beta$, APP, APPa, APP $\beta$, SYN, PSD95, GAP43, BACE $1, \beta$-actin, and GAPDH were obtained from Boster Biological Engineering Co., Ltd (Wuhan, China). 


\section{Hematoxylin-eosin (HE) staining}

The brain tissues were immersed in 4\% paraformaldehyde solution and fixed at room temperature for 24 $\mathrm{h}$, then dehydrated according to standard procedures, embedded, sliced $10 \mu \mathrm{m}$, baked slices, stained with $\mathrm{HE}$ and sealed slices with gum, etc. The pathological changes of each group of brain tissues were observed under a light microscope.

\section{Golgi staining for dendritic spines}

After anesthesia, three brains of mice were collected and fixed in 4\% paraformaldehyde solution for $24 \mathrm{~h}$. After fixation, the brain tissues were stained in Golgi staining solution for 14 days without light. After soaking for $48 \mathrm{~h}$, the brain tissues were transferred to a new Golgi staining solution. Next, the liquid was changed every three days. Brain tissues were taken out and placed in $15 \%$ sucrose solution for dehydration at $4^{\circ} \mathrm{C}$ for one day, and brain tissues were taken out and placed in $30 \%$ sucrose solution for dehydration at $4^{\circ} \mathrm{C}$ for two days. The brain tissues were taken out and washed successively with distilled water for $60 \mathrm{~s}$, concentrated ammonia for $45 \mathrm{~min}$, distilled water for one min, fixing solution for $45 \mathrm{~min}$ and distilled water for one min. The brain tissues were placed in $30 \%$ sucrose solution for dehydration at $4^{\circ} \mathrm{C}$ and avoided light for three days. After dehydration, slices of $100 \mu \mathrm{m}$ thickness were cut with a frozen slicer, and the slices were sealed with glycerin gelatin. The sections were observed under oil microscope, and the sections with the same position and field of view were taken photos. The Image processing software Image $\mathrm{J}$ was used to calculate the density of dendritic branches and dendritic spines in each section.

\section{Thioflavin S staining}

The brain tissue was placed in paraformaldehyde and sectioned $24 \mathrm{~h}$ later with paraffin embedding. Thioflavine-S was immersed in $0.125 \%$ thioflavine-S solution for $8 \mathrm{~min}$ in darkness. Wash the tablets with PBS for three times, five min each time, and then seal the tablets with sealing tablets. The deposition of $A \beta$ in the hippocampus of each group of mice was analyzed under microscope.

\section{Biochemical assays}

Levels or activities of SOD, CAT, GSH-Px, MDA, ALT, AST, ALP, TBIL in serum, as well as the levels of TNF-a, IL-1 $\beta$, IL- 6 in the brain were determined according to the manufacturer's instructions.

\section{Western blotting}

The brain tissue proteins were separated by SDS-PAGE and transferred to the PVDF membrane. Incubated the membrane with primary antibody diluted with primary antibody diluent at $4^{\circ} \mathrm{C}$ overnight. Diluted the secondary antibody 1:500 in TBST. HRP staining was used to detect immunoreactive bands. $\beta$-actin and GAPDH were protein loading controls. The gray intensity of the bands was quantified using Image $J$ software.

\section{Statistical Analysis}


All values are expressed as mean \pm SEM. The data were analyzed by one-way analysis of variance (ANOVA) followed by Turkeys test for post hoc analysis. Tests were performed on SPSS 20.0 system (Chicago, IL); $P \leqq 0.05$ was considered to be statistically significant. ${ }^{\wedge} P<0.05,{ }^{\wedge} \wedge P<0.01,{ }^{\wedge \wedge} \wedge<0.01$ vs. WT group; * $P<0.05$, ** $P<0.01$, *** $P<0.01$ vs. Tg group; $P<0.05$, \#\# $P<0.001$, \#\#\# $P<0.001$, vs. Mm group.

\section{Results}

\section{Chemical composition analysis of CG by HPLC-QQQ-MS}

The HPLC-QQQ-MS/MS method was established to characterize the chemical constituents of CG. The MS total ion current profiles of CG were presented in the positive and negative mode (Fig. 1a, b). A total of 28 compounds (Table 1) were identified by comparing the retention time and MS fragmentation behaviors with literature information [27-31]. Most of these compounds have been reported as the main bioactive components of each individual herb.

\section{CG + Mm rescued cognitive deficits in AD mice}

After treatment, we evaluated the spatial memory and autonomous exploration ability of AD mice by MWM and OFT. In the MWM test, compared with WT group, the Tg group showed an obviously memory impairment with longer EL $(P<0.001$, Fig. 2c, d). Moreover, the mice in Tg group crossed the platform and target quadrant (the quadrant of the hidden platform) less frequently than WT mice $(P<0.001$, Fig. 2e, f). After treatment, the trajectories of mice (CG, Mm, and CG + Mm group) tended to be normal (Fig. 2b), with swimming range primarily focusing on the second quadrant of the hidden platform. The EL was also significantly reduced by $\mathrm{CG}+\mathrm{Mm}$ treatment $(P<0.001$, Fig. $2 \mathrm{c}$, d). Meanwhile, target quadrant residence time and times of crossing through target platform of APP/PS1 mice treated by $\mathrm{CG}+\mathrm{Mm}$ were significantly increased $(P<0.001$, Fig. $2 \mathrm{e}, \mathrm{f})$.

OFT was used to observe various behaviors of mice after being released into an open environment, reflecting the neuropsychological activities of experimental animals. As consequence, there were significant differences in the total running times and the total squares acrossed (Fig. 3a-c), indicating that the activity and exploration ability of the mice treated by $C G+M m$ were significantly improved. Above all, the $C G+M m$ significantly prolonged the time in the target quadrant and running time, increased times of total squares acrossed, and reduce the EL of mice (Fig. 2c-f; Fig. 3b, c). The results suggested that CG + Mm can significantly improve the learning and memory abilities and autonomous activities of APP/PS1 mice.

\section{CG + Mm Rescues Pathological Changes in AD Mice}

HE staining and Golgi staining (Fig. 3d) was conducted to evaluate the effects of CG + Mm on neuronal loss in $A D$ mice brain. In the mice of Tg group, the cells in the hippocampus were arranged disorderly, and some cells presented the characteristics of neurodegeneration, with darkly stained, and exhibited triangulated and shrunken neuronal bodies. The morphology of neurons in the hippocampus of mice in 
the $C G, M m$, and $C G+M m$ group were improved to a certain extent, and the morphological characteristics of neurons were consistent, the cells were orderly and the cell structure was clear.

\section{CG + Mm improves synaptic function in AD mice}

The number of dendritic spines and the development of dendrites are closely related to the synaptic function of $A D$ mice [32]. Here, we used Golgi staining to assess the effects of $C G+M m$ on dendritic morphology. As a result, Fig. 3e, the hippocampus of APP/PS1 mice in Tg group showed a lower density of spines, and this reduction could be rescued by $C G, M m, C G+M m$. We next quantified the expression of synapse-related proteins in the hippocampus of $A D$ mice. Compared with the mice in $\mathrm{Tg}$ group, the expression of PSD95, SYN, and GAP43 in APP/PS1 mice treated with CG + Mm increased significantly ( $P$ $<0.01, P<0.001$, Fig. 4b). Moreover, the effect of CG combined with Mm was better than that of $\mathrm{Mm}$ alone. This suggests that CG combined with Mm to improve synaptic function may be achieved by upregulating the expression of PSD95, SYN, and GAP43 to regulate synaptic plasticity.

\section{CG enhanced the effects of $\mathrm{Mm}$ on reducing $\mathrm{A} \beta$ plaque deposition in AD mice}

The $A \beta$ has been proposed to play a key role in pathological progress [33], which accumulation and plaque deposition may induce dendritic and axonal atrophy, synaptic failure, and neuronal death [34, 35]. To confirm whether $\mathrm{CG}$ enhanced $\mathrm{Mm}$ alleviated cognitive impairment in $A D$ mice by reducing $A \beta$ plaque deposition, the brain sections were stained with thioflavin $S$ for determination of $A \beta$ plaques. Our study demonstrated that $C G$ could lower $A \beta$ deposition in the hippocampus compared to the $\mathrm{Tg}$ group and this treatment effect is stronger than that of $\mathrm{Mm}$, as shown in Fig. 4a. In this study, Mm did not appear to have a positive effect on reducing $A \beta$ deposition. By contrast, in the combined treatment group, this treatment has the strongest effect. The levels of BACE1, APP, APPa and APP $\beta$ in the hippocampus of AD mice were further confirmed with a Western blotting analysis. Similar to the immunofluorescence staining, APP levels in the hippocampus were significantly reduced in the CG + MM group $(P<0.001$, Fig. 4f), as well as levels of APP $\beta$ ( $P<0.001$, Fig. 4h), BACE1 $(P<0.001$, Fig. 4i). Conversely, the level of APPa increased significantly in CG + Mm group $(P<0.001$, Fig. $4 \mathrm{~g})$. In this study, we found that CG can enhance the effect of $\mathrm{Mm}$ in reducing $\mathrm{A} \beta$ deposition by down-regulating the expression of BACE1, APP and $A P P \beta$. The pathological changes of $A D$ were significantly reversed.

\section{Effects of CG + Mm on neuroinflammation and oxidative stress in the brain and serum of AD mice}

The MDA contents in serum for Tg group were significantly higher compared to the WT group $(P<0.001$, Fig. 5d). Moreover, the increase in MDA contents in serum was attenuated by $\mathrm{CG}+\mathrm{Mm}$ administration. As shown in Fig. 5a-c, the activities of SOD, GSH-Px as well as the levels of CAT in the Tg group were significantly lower compared to the WT group in serum $(P<0.001)$, whereas CG + Mm treatment significantly alleviated the reduction of MDA $(P<0.001$, Fig. $5 d)$. In addition, oral administration of CG + 
Mm increased the levels of SOD, GSH-Px, and CAT in serum. Neuroinflammation is another pathological change of AD. 6 In this study, we found that the level of inflammation in the hippocampus of APP/PS1 mice was signify-cantly increased (Levels of IL-1 $\beta$, IL-6, TNF-a were significantly increased, $P<0.001$, Fig. $5 \mathrm{e}-\mathrm{g}$ ), indicating the occurrence and development of neuroinflammation, while the therapeutic effect of Mm was limited. However, after Mm combined with CG, the development of inflammation was effectively controlled.

\section{Effects of CG + Mm on ALT, AST, ALP, and TBIL levels}

To determine whether CG combined with $\mathrm{Mm}$ has potential hepatotoxicity, we measured the serum levels of ALT, AST, ALP, and TBIL ( $P>0.05$, Fig. 5h-k). The results showed that there was no significant difference between the five groups, which shows that CG combined with $\mathrm{Mm}$ is safe.

\section{Discussion}

Current study, we observed that CG combined with Mm significantly improved the learning and memory abilities and autonomous activities of APP/PS1 mice, which are involved in decreasing ROS production, inflammatory cytokine expression (Fig. 5), and reducing $A \beta$ deposition in AD mice brain (Fig. 4). The main pathological features of $A D$ are progressive memory decline and cognitive decline [30]. More and more evidence showed that abnormal production of $A \beta$ is one of the important causes of $A D[36,37]$. Extracellular $A \beta$ oligomers trigger neuroinflammation and oxidative stress leading to cognitive decline with multiple types of neuronal damage in $A D$ patients $[38,39]$. Inhibition of $A \beta$ production and deposition is considered to be a potential treatment strategy for AD. In this study, Mm did not appear to have a positive effect on reducing $A \beta$ deposition. In comparison, there was an interesting result that CG had a better reducing $A \beta$ deposition activity than Mm. CG contains a number of active ingredients, as one of the active ingredients in CG, ferulic acid reverses cognitive deficits and mitigates AD-like pathology by altering amyloido-genic $\beta$-secretase APP cleavage both in mutant APP-overexpressing neuron-like cells and transgenic mouse, hence, ferulic acid is considered as a $\beta$-secretase modulator $[40,41]$. Rosmarinic acid suppresses $A D$ development by reducing $A \beta$ aggregation via increasing monoamine secretion [42]. Rhynchophylline suppresses soluble $A \beta$-induced impairment of spatial cognition function by inhibiting excessive activation of extrasynaptic NR2B-containing NMDA receptors [43]. Isorhynchophylline improves cognitive impairment in TgCRND8 mice via reducing $A \beta$ generation and deposition, neuroinflammation through inhibiting the activation of JNK signaling pathway [44]. Thus, the mentioned ingredients of CG might serve as the key effectors in alleviating $A \beta$ plaque burden and ameliorating cognitive decline during $A D$. Thus, we supposed that $C G+M m$ decreased $A \beta$ production and accumulation by inhibiting expression of BACE1 and APP in APP/PS1 mouse brain, indicating that CG + Mm was involved in A metabolism.

CG is a well-known Chinese patent medicine being sold in the current herbal market for years. To date, more than 100 biologically active compounds have been identified in CG. This herbal mixture is mainly used in treating headache and dizziness associated with cerebrovascular diseases in clinics [45]. Studies have shown that CG prevents aging mainly via suppression of oxidative stress response, such as 
decreasing NO and MDA levels, renewing activities of SOD, CAT, and GSH-Px, as well as decreasing AChE activity in the brain of D-gal-treated mice [45]. Previous researches proved that paeoniflorin exerts neuroprotective effects by alleviating $A \beta$ plaque burden, inhibiting astrocyte activation, and decreasing IL$1 \beta$ and TNF- $\alpha$ expression in the brain of 5XFAD mice [46]. Tetrahydropalmatine prevents the neuroinflammation and memory impairment in the D-gal treated rats by decreasing the expression of nuclear factor $\mathrm{K}$ (NF-KB) and glial fibrillary acidic protein [47]. Albiflorin ameliorates memory deficits in APP/PS1 mice by conferring synaptic protection and improving mitochondrial function, reducing $A \beta$ deposition and reactive oxygen species in the brain [48]. These components make CG may have good anti-inflammatory and anti-oxidative activities. And we were wondering whether CG combined with $\mathrm{Mm}$ could relieve neuroinflammation and oxidative damage. In the results of the present study, CG combined with Mm significantly reduced the level of MDA and increases the activity of SOD, CAT, and GSH-Px in serum; and reduced the content of inflammatory factors IL-1 $\beta$, IL-6, TNF-a in the hippocampus. On the other hand, the combined group did not cause an increase in serum AST, ALT, ALP, and TBIL levels, indicating that there is no liver toxicity after long-term treatment.

Synaptic loss is correlated with memory and cognitive dysfunction in AD [49]. Synaptic plasticity is thought to be fundamental to learning and memory ability in the brain [50]. Thus, improving synaptic dysfunction might be a vital method to postpone the progression of the neurodegenerative disease. Synaptophysin is a pre-synaptic marker commonly used to detect the density and distribution of synapses. Synaptophysin loss is an early event of $A D$ and is considered to be an important marker of synaptic changes [51]. PSD-95 is another important synaptic associated protein located in the postsynaptic region and plays an important role in synaptic plasticity [52]. In this study, Western blot analysis showed that the protein expression of synaptophysin and PSD-95 were significantly down-regulated in $\mathrm{Tg}$ group compared to the WT group. It is indicated that synaptic degeneration occurred in the mice of the $\mathrm{Tg}$ group. Our results showed that CG + Mm could restore the expression of synaptophysin and PSD-95, which implied that $C G$ could resist the synaptic disruption.

Above all, our research suggests that a combination group could reach a better attenuate Alzheimer-like pathology effect than either of them. In our opinion, CG as a mixture of a few of active ingredients may enhance $\mathrm{Mm}$ anti-AD effect by reducing $A \beta$ production and accumulation, neuroinflammation, oxidative damage and improving synaptic function through multiple signaling pathways and therefore could remedy $A D$ cognitive impairment. Thus, the combination of $C G$ with the Mm could be a better way to improve the treatment effects and life quality of $A D$ patients.

\section{Conclusions}

In conclusion, the present study has demonstrated that CG may enhance the Mm anti-AD effect of APP/PS1 mice. Based on these data, we hypothesized that the underlying mechanism of synergistic effect of $C G$ and $M m$ was reducing of $A \beta$ production via APP metabolic pathway and alleviating $A \beta$ associated pathological events, oxidative stress injury, chronic neuroinflammation, and synaptic injury. These results provide a rationale for future clinical use of CG in anti-AD like pathological develop-ment 
which could play a role as complementary medicine. Moreover, further studies are necessary to evaluate the exact underlying mechanism of $\mathrm{CG}$ and $\mathrm{CG}+\mathrm{Mm}$ at the cellular and molecular level.

\section{Abbreviations}

AD: Alzheimer's disease; CG: Cerebralcare Granule ${ }^{8} ;$ TCM: Traditional Chinese medicine; A 3 : amyloid- $\beta$; Mm: memantine hydrochloride; HE: Hematoxylin-eosin; ALT: Alanine aminotr-ansferase; AST: aspartate aminotransferase; ALP: alkaline phosphatase; TBIL: total bilirubin; APP: amyloid precursor protein; BACE1: $\beta$-secretase; SYN: synaptophysin; PSD95: postsynaptic density 95; GAP43: growth-associated protein 43; NMDA: Nmethyl-D-aspartate; CG: Cerebralcare granule ${ }^{\circledR}$; WT: Wild type; Tg: APP/PS1 mice transgenic mice; MDA: malondialdehyde; CAT: catalase; GSH-Px: glutathio-ne peroxidase; SOD: superoxide dismutase; IL-6: interleuk-inn-6; IL-1 $\beta$ : interleukin-1 $\beta$; TNF-a: tumour necrosis factor-a; EL: escape latency; MWM: Morris water maze; OFT: Open field test; ANOVA: one-way analysis of variance.

\section{Declarations}

\section{Acknowledgements}

Not applicable.

\section{Authors' contributions}

Ou Qiao, Xinyu Zhang, Changxiao Liu, and Wenyuan Gao conceived of and developed the study. Ou Qiao wrote the manuscript. Yi Zhang, Haixia Ji, Zhi Li, Xiaoying Han, Wenzhe Wang, Xia Li, and Juan wang performed the data acquisition and analysis. All authors read and approved the final manuscript.

\section{Funding}

This study was supported by the Science and Technology project of Tianjin (NO. 18ZXXYSY00080); National Natural Science Foundation of China (No. 81673535).

\section{Availability of data and materials}

The research data generated from this study is included within the article.

\section{Ethics approval and consent to participate}

All procedures in this study were approved and supervised by the Institutional Animal Care and Use Committee of Institute of Radiation Medicine Chinese Academy of Medical Sciences, and strictly obeyed the rules of animal experiment ethic to reduced number as well as sufering of animals.

\section{Consent for publication}

Not applicable. 


\section{Competing interests}

The authors have disclosed that no competing interest exists.

\section{Author details}

${ }^{1}$ Tianjin Key Laboratory for Modern Drug Delivery and High-Efficiency, School of Pharmaceutical Science and Technology, Tianjin University, Weijin Road, Tianjin 300072, China. ${ }^{2}$ The State Key Laboratories of Pharmacodynamics and Pharmacokinetics, Tianjin 300193, China.

\section{References}

1. Cummings J, Lee G, Ritter A, Zhong K. Alzheimer's disease drug development pipeline: 2018. Alzheimer's \& dementia (New York, N Y). 2018;4:195-214.

2. Lonnemann N, Hosseini S, Marchetti C, Skouras DB, Stefanoni D, D'Alessandro A, et al. The NLRP3 inflammasome inhibitor OLT1177 rescues cognitive impairment in a mouse model of Alzheimer's disease. Proc Natl Acad Sci U S A. 2020;117(50):32145-54.

3. Livingston G, Sommerlad A, Orgeta V, Costafreda SG, Huntley J, Ames D, et al Cohen-Mansfield J, et al. Dementia prevention, intervention, and care. Lancet. 2017;390(10113):2673-734.

4. Li Z, Li H, Zhao CH, Lv C, Zhong CJ, Xin WF, et al. Protective Effect of Notoginsenoside R1 on an APP/PS1 Mouse Model of Alzheimer\&aposs Disease by Up-Regulating Insulin Degrading Enzyme and Inhibiting Aß Accumulation. CNS Neurol Disord Drug Targets. 2015;14(3):360-9.

5. Pozueta J, Lefort R, Shelanski ML. Synaptic changes in Alzheimer's disease and its models. Neuroscience. 2013;251:51-65.

6. Zhu M, Wang X, Sun L, Marianne S, Erik H. Can inflammation be resolved in Alzheimer's disease? Ther Adv Neurol Disord. 2018;11:1-16.

7. Blasko I, Veerhuis R, Stampfer-Kountchev M, Saurwein-Teissl M, Grubeck-Loebenstein B. Costimulatory Effects of Interferon- $\gamma$ and Interleukin-1 $\beta$ or Tumor Necrosis Factor $a$ on the Synthesis of $A \beta 1-40$ and $A \beta 1-42$ by Human Astrocytes. Neurobiol Dis. 2000;7(6 Pt B):682-9.

8. Ren P, Chen JW, Li BX, Zhang MZ, Yang B, Guo XS, et al. Nrf2 Ablation Promotes Alzheimer's DiseaseLike Pathology in APP/PS1 Transgenic Mice: The Role of Neuroinflammation and Oxidative Stress. Oxid Med Cell Longev. 2020;(3):1-13.

9. Gyorffy BA, Toth V, Torok G, Gulyassy P, Kovacs RA, Vadaszi H, et al. Synaptic mitochondrial dysfunction and septin accumulation are linked to complement-mediated synapse loss in an Alzheimer's disease animal model. Cell Mol Life Sci. 2020;77(24):5243-58.

10. Yang LL, Xue Y, Wei JC, Dai Q, Li P. Integrating Metabolomic Data With Machine Learning Approach for Discovery of Q-markers From Jinqi Jiangtang Preparation Against Type 2 Diabetes. Chin Med. 2021;16:30. 
11. Wang DM, Liu L, Li SQ, Wang CY. Effects of paeoniflorin on neurobehavior, oxidative stress, brain insulin signaling, and synaptic alterations in intracerebroventricular streptozotocin-induced cognitive impairment in mice. Physiol Behav. 2018;191:12-20.

12. Mori T, Koyama N, Yokoo T, Segawa T, Maeda M, Sawmiller D, et al. Gallic acid is a dual a/ $\beta$ secretase modulator that reverses cognitive impairment and remediates pathology in Alzheimer mice. J Biol Chem. 2020;295:16251-66.

13. Thingore $C, K$ shirsagar $V$, Juvekar $A$. Amelioration of oxidative stress and neuroinflammation in lipopolysaccharide-induced memory impairment using Rosmarinic acid in mice. Metab Brain Dis. 2021;36(2):299-313.

14. Lee TK, Kang IJ, Kim B, Sim HJ, Kim DW, Ahn JH, et al. Experimental Pretreatment with Chlorogenic Acid Prevents Transient Ischemia-Induced Cognitive Decline and Neuronal Damage in the Hippocampus through Anti-Oxidative and Anti-Inflammatory Effects. Molecules. 2020;25(16):3578.

15. Meng GL, Meng XL, Ma XY, Zhang GP, Hu XL, Jin AP, et al. Application of Ferulic Acid for Alzheimer's Disease: Combination of Text Mining and Experimental Validation. Front Neuroinform. 2018;12:31.

16. Li XW, Tong L, Li YF, Sun GX, Yang DL, Herry S, et al. Simultaneous determination of seven alkaloids in rat plasma by UFLC-MS/MS and its application to a pharmacokinetic study after oral administration of Cerebralcare Granule. J Chromatogr B Analyt Technol Biomed Life. 2016;1017:2835 .

17. Wang XY, Ma XH, Li W, Chu Y, Guo JH, Li SM, et al. Simultaneous determination of five phenolic components and paeoniflorin in rat plasma by liquid chromatography-tandem mass spectrometry and pharmacokinetic study after oral administration of Cerebralcare granule (R). J Pharm Biomed Anal. 2013;86:82-91.

18. Lin YL, Yang XG, Lu M, Zheng WJ, Zhang J, Zhuang HQ, et al. Herbal compound triptolide synergistically enhanced antitumor activity of vasostatin120-180. Anticancer Drugs. 2013;24(9):945-57.

19. Wang XN, Zhao HF, Liu LM, Niu P, Zhai C, Li JN, et al. Hejie Zhitong prescription promotes sleep and inhibits nociceptive transmission-associated neurotransmitter activity in a rodent migraine model. Chin Med. 2020;15:105.

20. Xia JF, Rong L, Sawakami T, Inagaki Y, Song PP, Hasegawa K, et al. Shufeng Jiedu Capsule and its active ingredients induce apoptosis, inhibit migration and invasion, and enhances doxorubicin therapeutic efficacy in hepatocellular carcinoma. Biomed Pharmacother. 2018;99:921-30.

21. Zheng F, Zhao YY, Li X, Tang Q, Wu JJ, Wu WY, et al. The repression and reciprocal interaction of DNA methyltransferase 1 and specificity protein 1 contributes to the inhibition of MET expression by the combination of Chinese herbal medicine FZKA decoction and erlotinib. J Ethnopharmacol. 2019;239:111928.

22. Zhang XQ, Ding YW, Chen JJ, Xiao X, Zhang W, Zhou L, et al. Xiaoaiping injection enhances paclitaxel efficacy in ovarian cancer via pregnane $X$ receptor and its downstream molecules. $J$ Ethnopharmacol. 2020;261:113067. 
23. Li MF, Xie L, Li Y, Liu J, Nie GN, Yang HY. Synergistic effect of Huyang Yangkun Formula and embryonic stem cells on 4-vinylcyclohexene diepoxide induced premature ovarian insufficiency in mice. Chin Med. 2020;15:83.

24. Olivares D, Deshpande VK, Shi Y, Lahiri DK, Greig NH, Rogers JT, et al. N-Methyl D-Aspartate (NMDA) Receptor Antagonists and Memantine Treatment for Alzheimer's Disease, Vascular Dementia and Parkinson's Disease. Curr Alzheimer Res. 2012;9(6):746-58.

25. Sinforiani E, Pasotti C, Chiapella L, Malinverni P, Zucchella C. Memantine in Alzheimer's disease: experience in an Alzheimer's disease assessment unit. Aging Clin Exp Res. 2012;24(2):193-6.

26. Zhang JH, Yu LJ, Hui Y, Zhen H, Su J, Ling C, et al. Huatuo Zaizao pill ameliorates cognitive impairment of APP/PS1 transgenic mice by improving synaptic plasticity and reducing $A \beta$ deposition. BMC Complement Altern Med. 2018;18(1):167.

27. Yang M, Sun JH, Lu ZQ, Chen GT, Guan SH, Liu X, et al. Phytochemical analysis of traditional Chinese medicine using liquid chromatography coupled with mass spectrometry. J Chromatogr. 2008;1216(11):2045-62.

28. Fernand VE, Dinh DT, Washington SJ, Fakayode SO, Losso JN, van Ravenswaay RO, et al. Determination of pharmacologically active compounds in root extracts of Cassia alata L. by use of high performance liquid chromatography. Talanta. 2008;74(4):896-902.

29. Ding B, Zhou T, Fan GR, Hong ZY, Wu YT. Qualitative and quantitative determination of ten alkaloids in traditional Chinese medicine Corydalis yanhusuo WT Wang by LC-MS/MS and LC-DAD. J Pharm Biomed Anal. 2007;45(2):219-26.

30. Chen L, Qi J, Chang YX, Zhu DN, Yu BY. Identification and determination of the major constituents in Traditional Chinese Medicinal formula Danggui-Shaoyao-San by HPLC-DAD-ESI-MS/MS. J Pharm Biomed Anal. 2009;50(2):127-37.

31. Zhang HY, Hu P, Luo GA, Liang QL, Wang YL, Yan SK, et al. Screening and identification of multicomponent in Qingkailing injection using combination of liquid chromatography/time-of-flight mass spectrometry and liquid chromatography/ion trap mass spectrometry. Anal Chim Acta. 2006;577(2):190-200.

32. Long QH, Wu YG, He LL, Ding L, Tan AH, Shi HY, et al. Suan-Zao-Ren Decoction ameliorates synaptic plasticity through inhibition of the A $\beta$ deposition and JAK2/STAT3 signaling pathway in AD model of APP/PS1 transgenic mice. Chin Med. 2021;16:14.

33. Hardy J, Selkoe DJ. Medicine - The amyloid hypothesis of Alzheimer's disease: Progress and problems on the road to therapeutics. Science. 2002;297(5580):353-6.

34. Kastanenka KV, Hou SS, Shakerdge N, Logan R, Feng D, Wegmann S, et al. Optogenetic Restoration of Disrupted Slow Oscillations Halts Amyloid Deposition and Restores Calcium Homeostasis in an Animal Model of Alzheimer's Disease. PLoS One. 2017;12(1):e0170275.

35. Fol R, Braudeau J, Ludewig S, Abel T, Weyer SW, Roederer JP, et al. Viral gene transfer of APPs alpha rescues synaptic failure in an Alzheimer's disease mouse model. Acta Neuropathol. 2016;131(2):247-66. 
36. Desgranges B, Baron JC, de la Sayette V, Petit-Taboue MC, Benali K, Landeau B, et al. The neural substrates of memory systems impairment in Alzheimer's disease - A PET study of resting brain glucose utilization. Brain. 1998;121:611-31.

37. Xia DY, Huang X, Bi CF, Mao LL, Peng LJ. PGC-1a or FNDC5 Is Involved in Modulating the Effects of $A \beta 142$ Oligomers on Suppressing the Expression of BDNF, a Beneficial Factor for Inhibiting Neuronal Apoptosis, A Deposition and Cognitive Decline of APP/PS1 Tg Mice. Front Aging Neurosci. 2017;9:65.

38. Cavallucci V, D’Amelio M, Cecconi F. A $\beta$ Toxicity in Alzheimer's Disease. Mol Neurobiol. 2012;45(2):366-78.

39. Reiserer RS, Harrison FE, Syverud DC, McDonald MP. Impaired spatial learning in the APP(Swe) + PSEN1 Delta E9 bigenic mouse model of Alzheimer's disease. Genes Brain Behavior. 2007;6(1):5465.

40. Mori T, Koyama N, Guillot-Sestier MV, Tan J, Town T. Ferulic Acid Is a Nutraceutical $\beta$-Secretase Modulator That Improves Behavioral Impairment and Alzheimer-like Pathology in Transgenic Mice. PLoS One. 2013;8:e55774.

41. Mori T, Koyama N, Tan J, Segawa T, Maeda M, Town T. Combined treatment with the phenolics (-)epigallocatechin-3-gallate and ferulic acid improves cognition and reduces Alzheimer-like pathology in mice. J Biol Chem. 2019;294(8):2714-31.

42. Hase T, Shishido S, Yamamoto S, Yamashita R, Nukima H, Taira S, et al. Rosmarinic acid suppresses Alzheimer's disease development by reducing amyloid $\beta$ aggregation by increasing monoamine secretion. Sci Rep. 2019;9:8711.

43. Yang Y, Ji WG, Zhu ZR, Wu YL, Zhang ZY, Qu SC. Rhynchophylline suppresses soluble Aß 1-42 induced impairment of spatial cognition function via inhibiting excessive activation of extrasynaptic NR2B-containing NMDA receptors. Neuropharmacology. 2018;135:100-12.

44. Li HQ, Ip SP, Yuan QJ, Zheng GQ, Tsim KKW, Dong TTX, et al. Isorhynchophylline ameliorates cognitive impairment via modulating amyloid pathology, tau hyperphosphorylation and neuroinflammation: Studies in a transgenic mouse model of Alzheimer's disease. Brain Behavior Immunity. 2019;82:264-78.

45. Qu Z, Yang HG, Zhang JZ, Huo LQ, Chen H, Li YM, et al. Cerebralcare Granule(A (R)), a Chinese Herb Compound Preparation, Attenuates d-Galactose Induced Memory Impairment in Mice. Neurochem Res. 2016;41(9):2199-214.

46. Kong YY, Peng QJ, Lv N, Yuan J, Deng ZR, Liang XL, et al. Paeoniflorin exerts neuroprotective effects in a transgenic mouse model of Alzheimer's disease via activation of adenosine $A(1)$ receptor. Neurosci Lett. 2020;730:13501.

47. Qu Z, Zhang JZ, Yang HG, Huo LQ, Gao J, Chen H,et al. Protective effect of tetrahydropalmatine against D-galactose induced memory impairment in rat. Physiol Behav. 2016;154:114-25.

48. Xu YJ, Mei Y, Shi XQ, Zhang YF, Wang XY, Guan L, et al. Albiflorin ameliorates memory deficits in APP/PS1 transgenic mice via ameliorating mitochondrial dysfunction. Brain Res. 2019;1719:113- 
23.

49. Selkoe DJ, Schenk D. Alzheimer's disease: Molecular understanding predicts amyloid-based therapeutics. Annu Rev Pharmacol Toxicol. 2003;43:545-84.

50. Losonczy A, Makara JK, Magee JC. Compartmentalized dendritic plasticity and input feature storage in neurons. Nature. 2008;452(7186):436-41.

51. Masliah E, Mallory M, Alford M, DeTeresa R, Hansen LA, McKeel DW. Altered expression of synaptic proteins occurs early during progression of Alzheimer's disease. Neurology. 2001;56(1):127-9.

52. El-Hussein AE, Schnell E, Chetkovich DM, Nicoll RA, Bredt DS. PSD-95 involvement in maturation of excitatory synapses. Science. 2000;290(5495):1364-8.

\section{Table}

Due to technical limitations, Table 1 is only available as a download in the supplemental files section

\section{Figures}



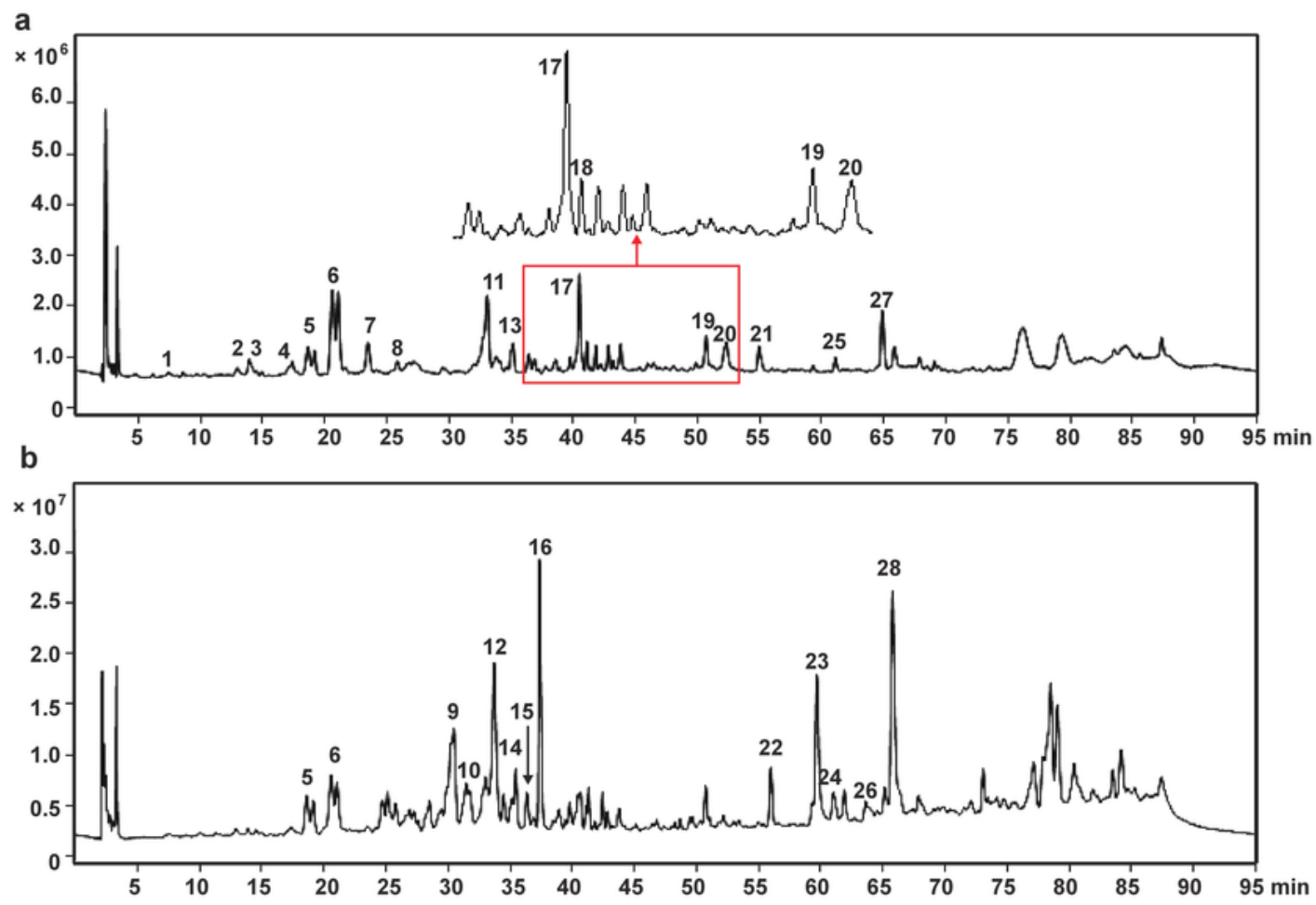

C

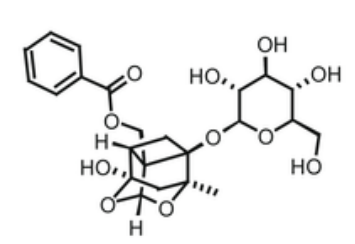

paeoniflorin<smiles>O=C(C=Cc1ccc(O)c(O)c1)OC1CC(O)C[C@@H](O)CC1C(=O)O</smiles>

chlorogenic acid

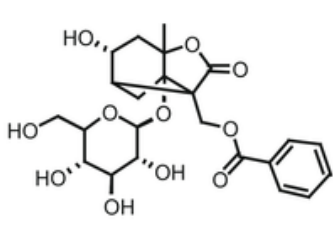

albiflorin<smiles>O=C(O)C=Cc1ccc(O)c(O)c1</smiles>

caffeic acid<smiles>O=C(/C=C/c1ccc(O)c(O)c1)OC(Cc1ccc(O)c(O)c1)C(=O)O</smiles>

rosmarinic acid<smiles>COc1cc(/C=C/C(=O)O)ccc1O</smiles>

ferulic acid<smiles>O=C(O)c1cc(O)c(O)c(O)c1</smiles>

gallic acid<smiles>COc1cc2c(cc1OC)C1Cc3ccc(OC)c(OC)c3CN1CC2</smiles>

tetrahydropalmatine

\section{Figure 1}

The chemical composition analysis of CG. (a) Total ion chromatogram of GC in negative ion mode; (b) Total ion chromatogram of CG in positive ion mode. (c) The chemical structures of eight active ingredients in CG. 


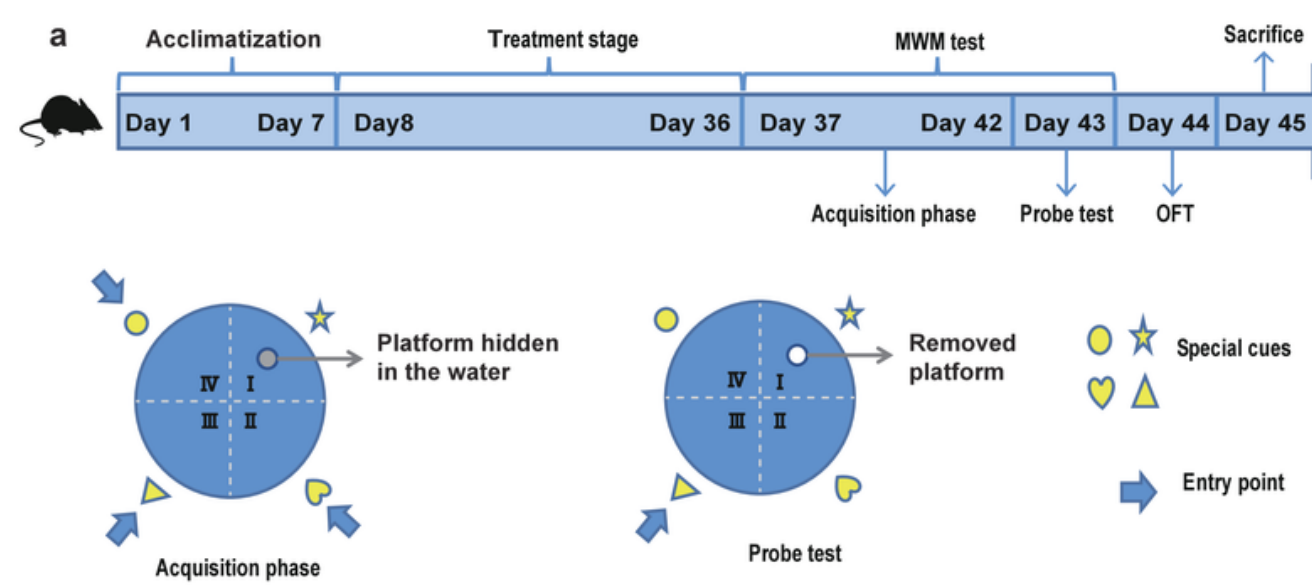

b

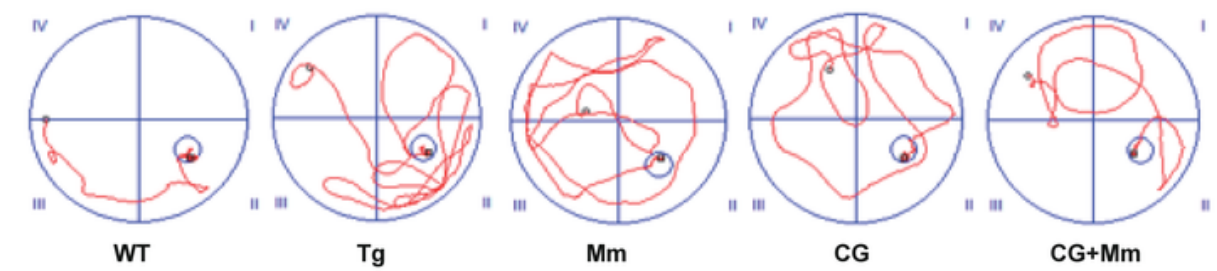

c

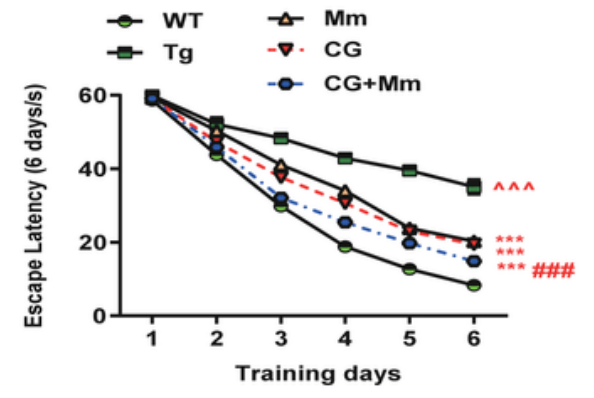

d

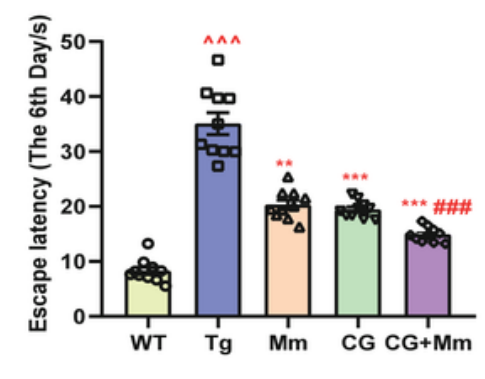

e
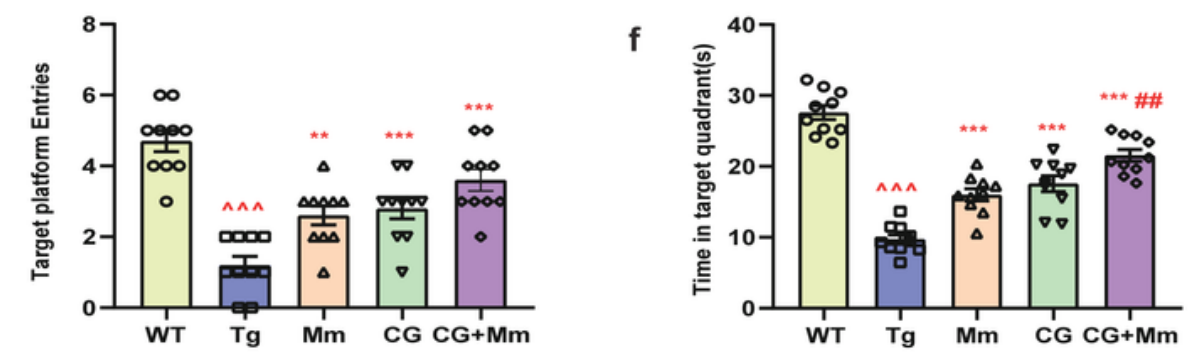

\section{Figure 2}

The scheme of experiment and MWM test. (a) The scheme of experiment to determine the effect of CG on APP/PS1 memory loss. (b-f) MWM test was conducted on APP/PS1 mice. (b) The representative traces on the last day during acquisition phase. (c) Escape latency trend for six consecutive days. (d) Escape latency on the sixth day. (e) Times of passing through platform. (f) Time in the target quadrant. ${ }^{\wedge} \mathrm{P}<$ 



$P<0.001$, \#\#\# $P<0.001$, vs. Mm group $(n=10)$.

a

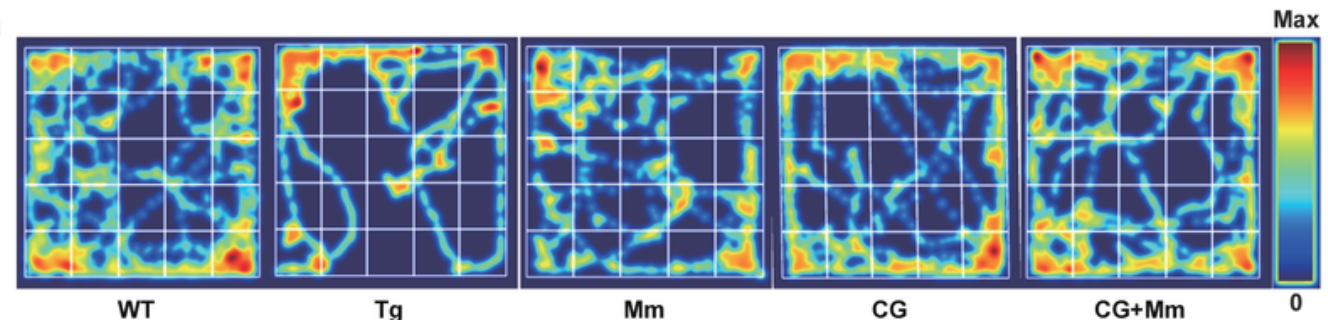

b
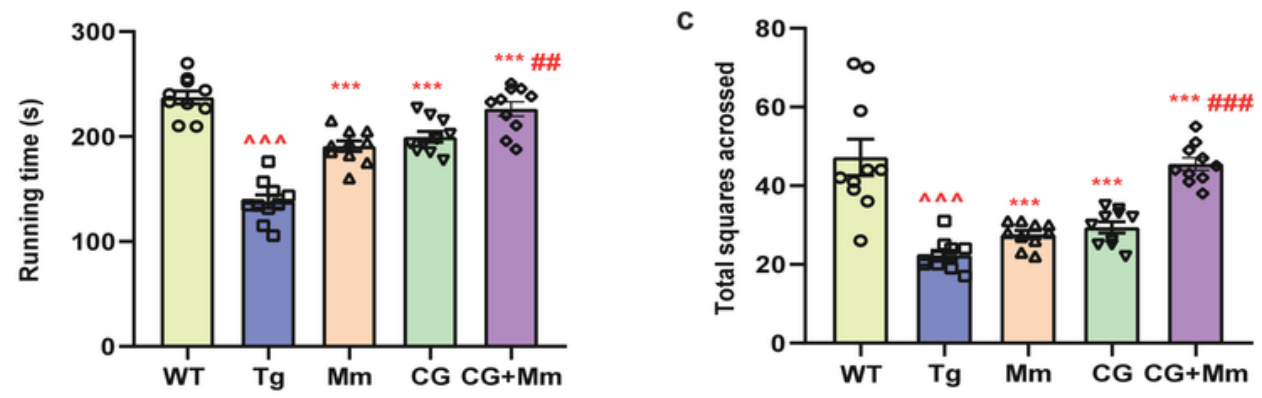

d

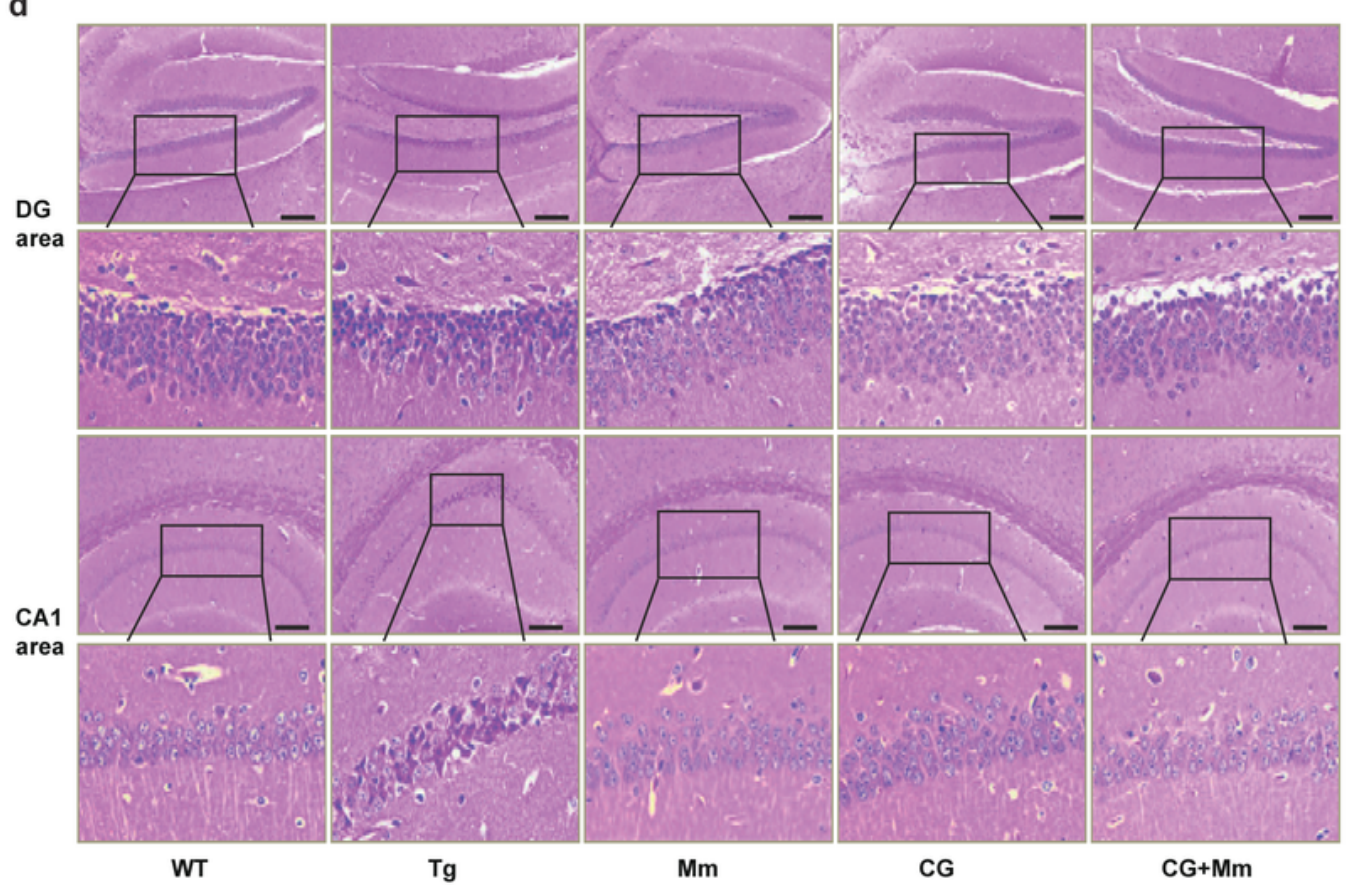

e
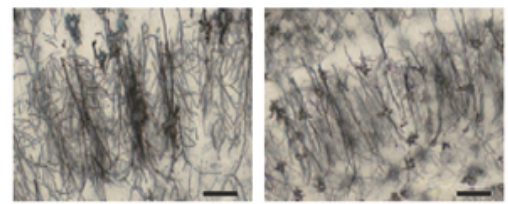

$\mathrm{Tg}$

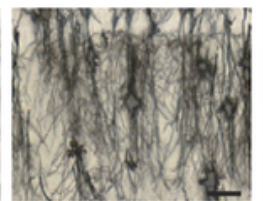

$\mathrm{Mm}$

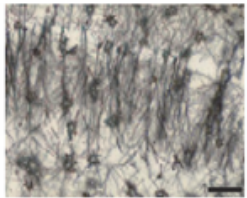

CG



$\mathrm{CG}+\mathrm{Mm}$

\section{Figure 3}

OFT and CG alleviated neuronal damage and improves synaptic function in mice brain. (a-c) OFT was conducted on APP/PS1 mice $(n=10)$. (a) The representative record of motion trajectories showed the locomotor path of all groups of mice. (b) Runnning time. (c) Total squares acrossed. (d) HE-stained 
images of hippocampal CA1 and DG area in APP/PS1. Scale bar $=200 \mu \mathrm{m}$. In APP/PS1 mice, the damaged neurons were deeply stained, and the neuron bodies were atrophied and appeared triangular. Cells are arranged indisorder with a slightly changed cell polarity. By contrast, treatment with CG, Mm, and $C G+M m$ significantly inhibited the histopathological damage. (e) Golgi staining of the hippocampus, Scale bar $=10 \mu \mathrm{m} .{ }^{\wedge} \mathrm{P}<0.05,{ }^{\wedge \wedge} \mathrm{P}<0.01$, ${ }^{\wedge \wedge} \mathrm{P}<0.01$ vs. WT group; * $\mathrm{P}<0.05$, ** $\mathrm{P}<0.01$, *** $P<0.01$ vs. Tg group; \# $P<0.05$, \#\# $P<0.001$, \#\#\# $P<0.001$, vs. Mm group $(n=10)$.

a
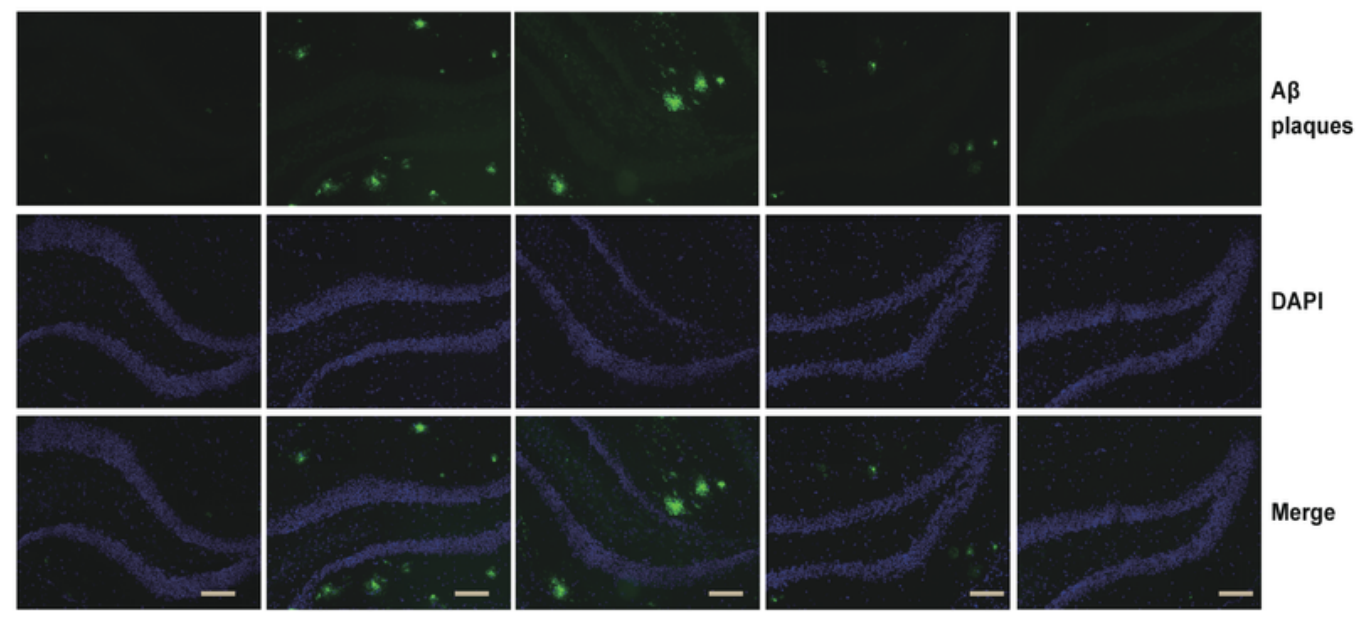

WT

$\mathrm{Tg}$

$\mathrm{Mm}$

CG

$\mathrm{CG}+\mathrm{Mm}$

b
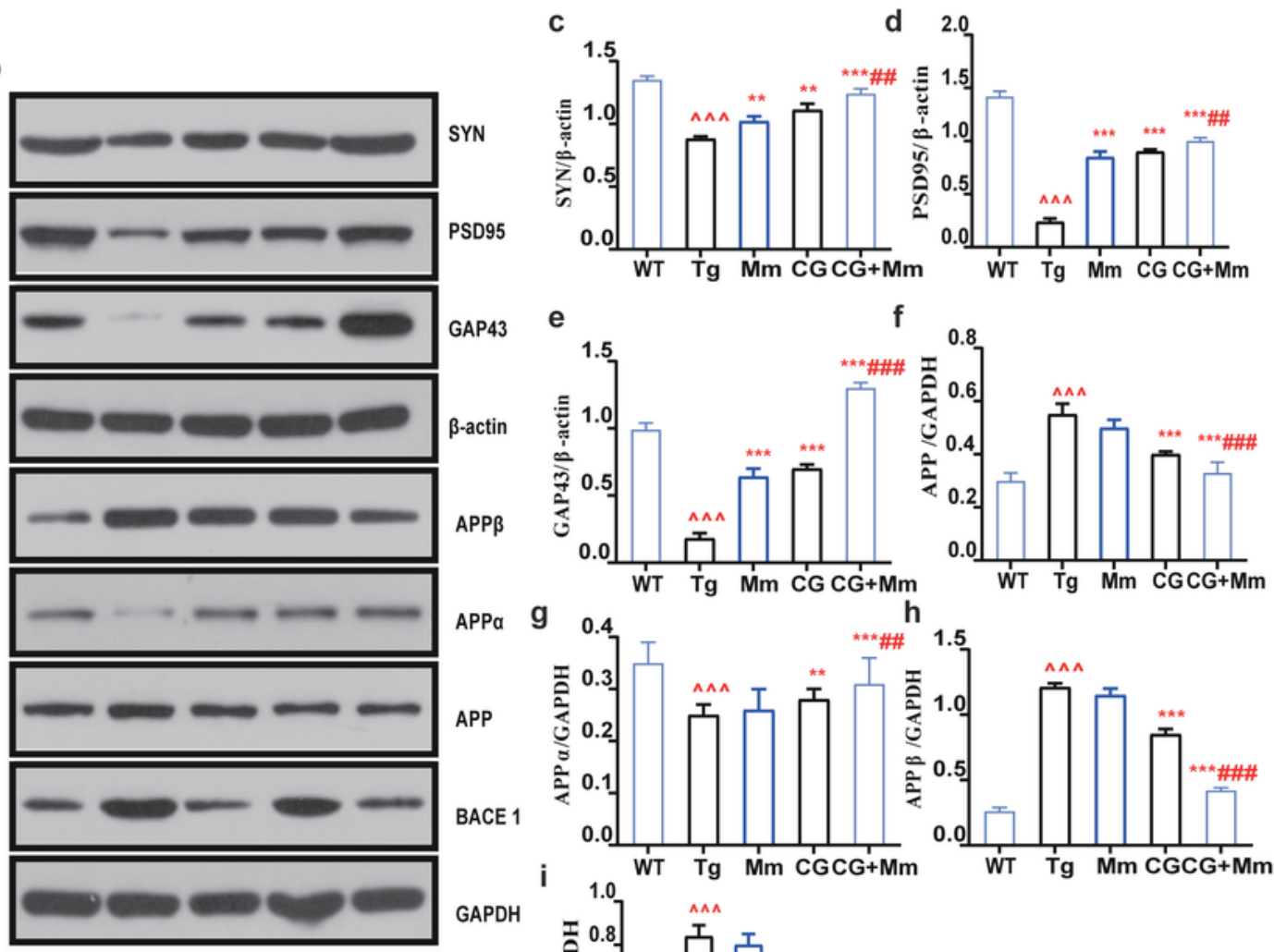
h

$\begin{array}{lllll}\text { WT } & \mathrm{Tg} & \mathrm{Mm} \quad \mathrm{CG} & \mathrm{CG}+\mathrm{Mm}\end{array}$ GAPDH
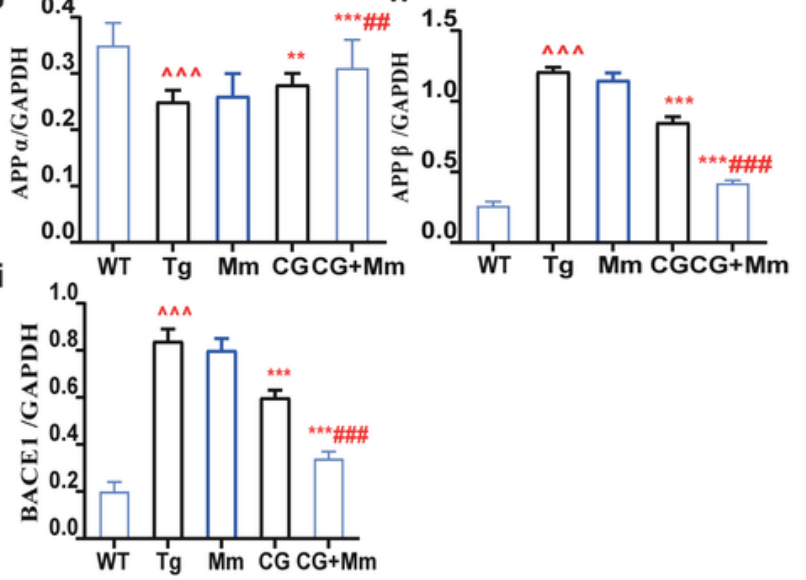

Figure 4 
CG enhanced the effects of $\mathrm{Mm}$ on reducing $A \beta$ plaque deposition In the hippocampus. (a) Immunofluorescence for $A \beta$ in the hippocampus of the APP/PS1 mice. Scale bar $=100 \mu \mathrm{m}$. (b) The protein levels of SYN, PSD95, GAP43, APP $\beta, A P P a, A P P$, and BACE1 were measured by Western blotting in the hippocampus of the different groups $(n=10)$. ( $(c-i)$ Quantitative analysis of SYN, PSD95, GAP43, APP $\beta, A P P a, A P P$, and BACE1 expression, respectively. ${ }^{\wedge} \mathrm{P}<0.05,{ }^{\wedge} \wedge \mathrm{P}<0.01,{ }^{\wedge \wedge} \mathrm{P} P<0.01$ vs. WT group; *

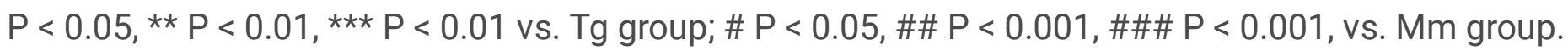
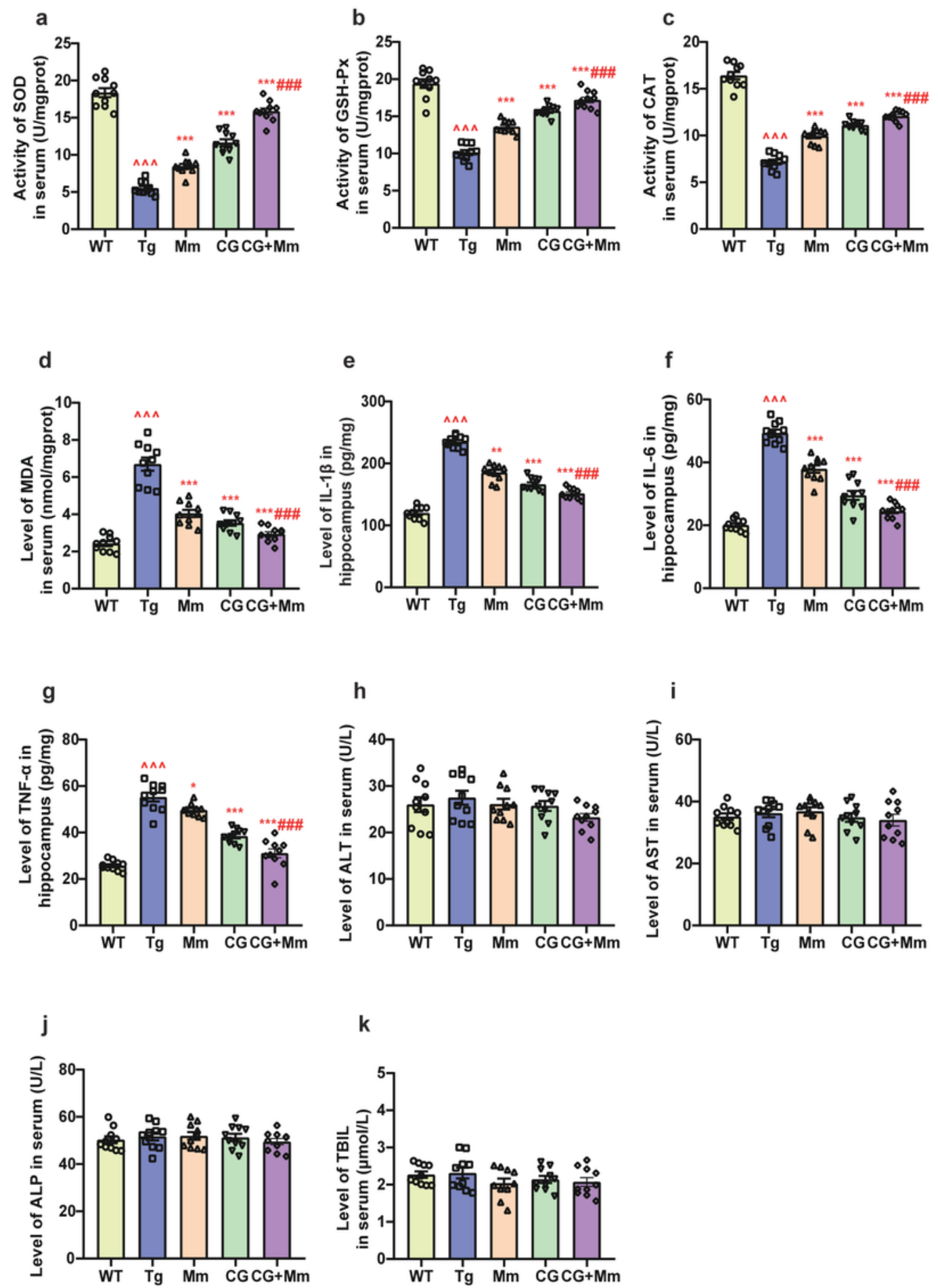

Figure 5 
Effects of $C G+M m$ on the neuroinflammation, oxidative stress, and liver function in vivo. (a-c) The activities of SOD, GSH-Px, and CAT in serum, respectively. (d) The level of MDA in serum. (e-g) The levels of IL $1 \beta$, IL-6, and TNF $a$ in the hippocampus, respectively. (h-k) The levels of ALT, AST, ALP, and TBIL in serum, respectively. ${ }^{\wedge} P<0.05,{ }^{\wedge} \mathrm{P}<0.01,{ }^{\wedge \wedge} \mathrm{A} P<0.01$ vs. WT group; ${ }^{*} \mathrm{P}<0.05$, ${ }^{\star \star} \mathrm{P}<0.01$, ${ }^{\star \star \star} \mathrm{P}<0.01$ vs. Tg group; \# P<0.05, \#\# P<0.001, \#\#\# P<0.001, vs. Mm group $(n=10)$.

\section{Supplementary Files}

This is a list of supplementary files associated with this preprint. Click to download.

- Table1.xls 